\title{
Evaluation of a.c. conductivity behaviour of graphite filled polysul- phide modified epoxy composites
}

\author{
NAVIN CHAND* and DEEPAK JAIN \\ Regional Research Laboratory, Hoshangabad Road, Habibganj Naka, Bhopal 462 026, India
}

MS received 30 December 2003; revised 1 March 2004

\begin{abstract}
Composites of epoxy resin having different amounts of graphite particles have been prepared by solution casting method. Temperature dependence of dielectric constant, $\tan \delta$ and a.c. conductivity was measured in the frequency range, 1-20 $\mathrm{kHz}$, temperature range, $40-180^{\circ} \mathrm{C}$ for $0.99,1.96$ and $2.91 \mathrm{wt} \%$ graphite filled and unfilled epoxy composites. It was observed that the dielectric constant, $\tan \delta$ and a.c. conductivity increase with increasing temperature. Near the transition temperature the materials show anomalous behaviour for the observed properties. Peaks of dielectric constant, $\tan \delta$ and a.c. conductivity were observed to shift towards lower temperature with increasing frequency. Clear relaxation $\left(\tan \delta\right.$ ) peaks around $169^{\circ} \mathrm{C}$ were observed in epoxy resin, which shifted to lower temperature side on increasing the frequency. Addition of $2.91 \mathrm{wt} \%$ graphite shifted the $\tan \delta$ peaks towards higher temperature side by creating hindrances to the rotation of polymer dipoles. Addition of $2.91 \mathrm{wt} \%$ graphite leads to an increased relaxation time $\tau$ of dipoles in polysulphide epoxy from $1.44 \times 10^{-5}-3.92 \times 10^{-5}$ (s) at $90^{\circ} \mathrm{C}$ by creating the hindrance to the rotation of dipoles.
\end{abstract}

Keywords. a.c. conductivity; graphite; epoxy.

\section{Introduction}

Epoxies are widely used in insulation, such as electrical machinery, switchgear and bushings in transformers $(\mathrm{Wu}$ and Tung 1995). Polymers have a very low concentration of free charge carriers, and thus are non conductive and transparent to electromagnetic radiation. Due to this reason they are not suitable for use as enclosures for electronic equipment because they cannot shield it from outside radiation. Also they cannot prevent the escape of radiation from the component. Polymers cannot provide protection against electrostatic discharge in handling sensitive electronic devices. This drawback has led to the development of electrically conductive polymers such as inherently conductive polyaniline or polymers filled with conductive particles. Beyond a critical concentration of filler polymer becomes conductive. This formation of a network permits the movement of charge carriers of the fillers through the matrix and so the composites achieve a certain degree of electrical conductivity (Tstra and Freidrich 2003). Several fillers can be added to the insulating polymeric matrix in order to achieve different conductivity ranges. Filled polymers are required for a variety of industrial applications (Delmonte 1990; Neelakanta 1995).

Graphite epoxy composites can have potential use in the area of thermoelectric power generation. Wu and Tung (1995) reported dielectric properties of pure epoxy resin

\footnotetext{
*Author for correspondence
}

in the temperature range -50 to $70^{\circ} \mathrm{C}$ and found a $\beta$ relaxation peak in the low temperature range of -30 to $-20^{\circ} \mathrm{C}$ due to the motion of diester segments introduced in the pure epoxy crosslinking network by the reaction of acid anhydride. They studied the relaxation response in a very limited temperature range.

Determination of a.c. conductivity behaviour of graphite filled polysulphide modified epoxy composite is very necessary for finding its suitable application. In this paper, graphite particles have been incorporated into polysulphide modified epoxy resin. Dielectric constant, $\tan \delta$ and a.c. conductivity have been determined at different temperatures and frequencies and analysed.

\section{Materials and methods}

A commercial type polysulphide modified epoxy resin twopart system having density $1.11 \mathrm{~g} / \mathrm{cm}^{3}$ was supplied by $\mathrm{M} / \mathrm{s}$ Chouksay Chemicals Pvt. Ltd., India. Graphite used in this study was obtained from HEG India. Composition of ingredients used in making composites are listed in table 1.

\subsection{Composite preparation}

Weighed amounts of dried graphite particles were mechanically mixed with polysulphide epoxy resin at room temperature until a homogeneous mixture was obtained. The homogeneous mixture was then poured into the mold cavity of $10 \mathrm{~mm}$ diameter. The curing was carried out at room temperature for $24 \mathrm{~h}$ cylindrical rod $(10 \mathrm{~mm}$ diameter $)$ obtained and cured further for 7 days at room temperature, 
which was cut into the pellets form of $2 \mathrm{~mm}$ thickness. Uniformity of surfaces was obtained by polishing the sample using polishing cloth. Both sides of the sample were coated by using a air drying type graphite conducting paint.

\subsection{A.c. conductivity measurements}

Capacitance and $\tan \delta$ values were measured by using a Hewlett-Packard LCR Meter model 4274A in the temperature range $40-180^{\circ} \mathrm{C}$. Heating rate was kept constant at $1^{\circ} \mathrm{C} / \mathrm{min}$.

$$
\varepsilon^{\prime}=C / C_{0},
$$

Table 1. Composition of ingredients.

\begin{tabular}{lcc}
\hline S1. No. & $\begin{array}{c}\text { Polysulphide modified } \\
\text { epoxy (wt } \%)\end{array}$ & Graphite (wt\%) \\
\hline 1. & 100 & 00 \\
2. & 99.01 & 0.99 \\
3. & 98.04 & 1.96 \\
4. & 97.09 & 2.91 \\
\hline
\end{tabular}
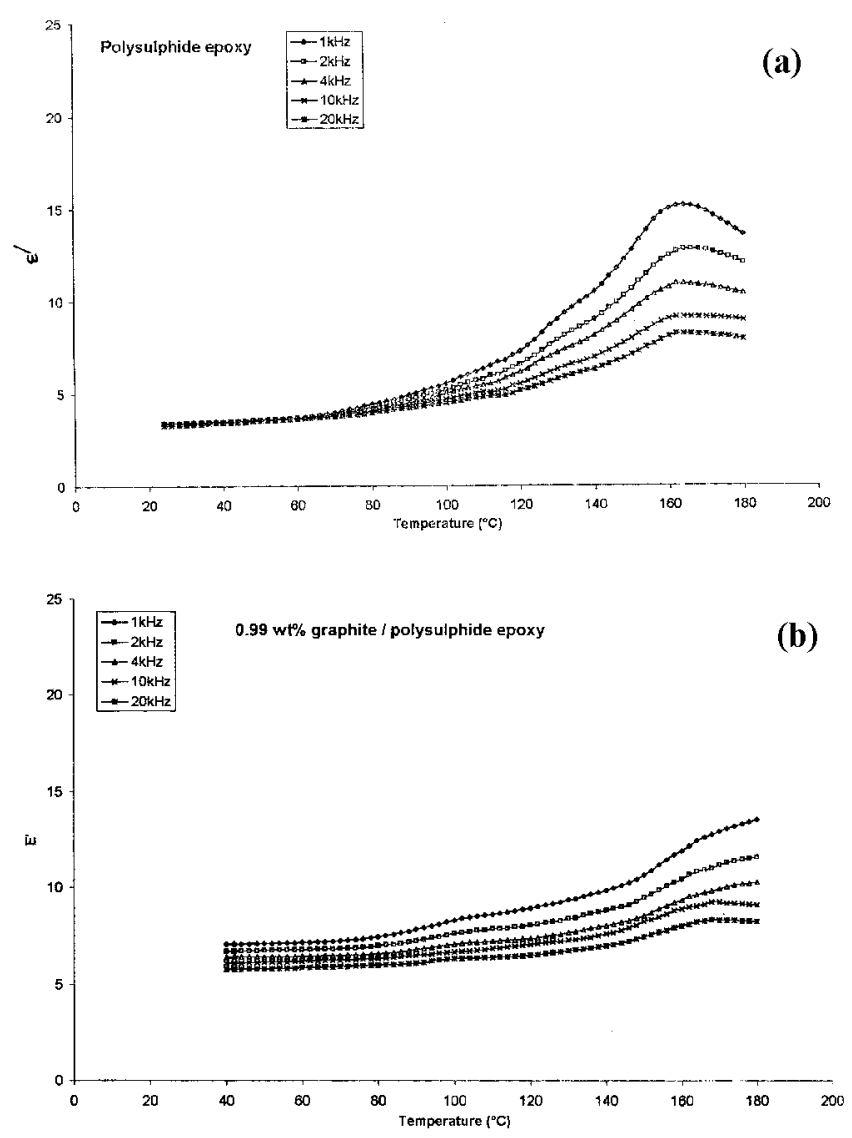

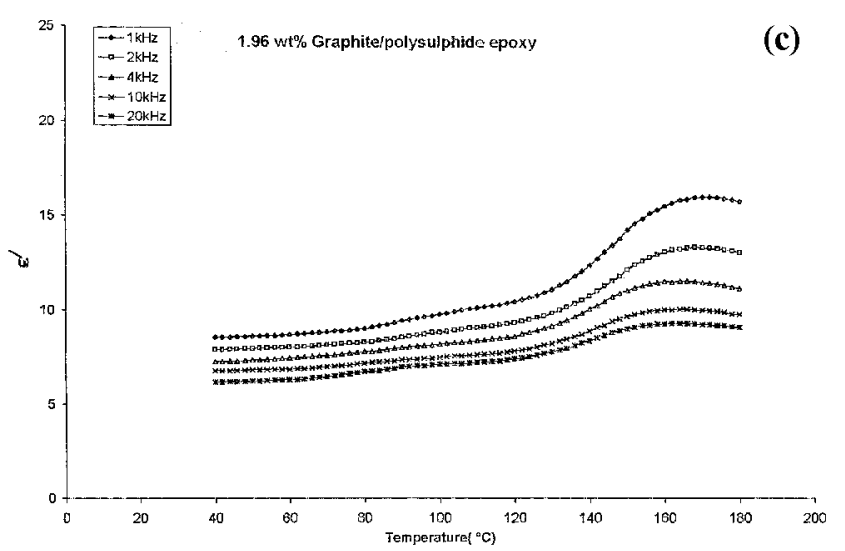

where $C$ and $C_{0}$ are the capacitance of the electrodes with and without dielectric, respectively; $C_{0}$ is given by

$$
C_{0}=[(0.08854 A) / d] \mathrm{pF},
$$

where $A\left(\mathrm{~cm}^{2}\right)$ is the area of the electrodes and $d(\mathrm{~cm})$ the thickness of the sample, a.c. conductivity $(\sigma)$ was calculated using the relation

$$
\sigma_{\text {a.c. }}=\varepsilon_{0} \omega \varepsilon^{\prime} \tan \delta,
$$

where $\varepsilon_{0}$ is the permittivity of the free space $\left(8.85 \times 10^{-12}\right.$ $\mathrm{Fm}^{-1}$ ), $\tan \delta$ the dissipation factor and $\omega$ the angular frequency, which is equal to $2 \pi f$.

\section{Results and discussion}

The effect of temperature on dielectric constant $\left(\varepsilon^{\prime}\right)$ of graphite filled and unfilled polysulphide modified epoxy has been determined in the temperature range, $40-180^{\circ} \mathrm{C}$.

Figure 1(a) shows the variation of dielectric constant $\left(\varepsilon^{\prime}\right)$ with temperature for polysulphide modified epoxy resin at $1,2,4,10$ and $20 \mathrm{kHz}$ frequencies. It was observed that $\varepsilon^{\prime}$ increased with increasing temperature and decreased

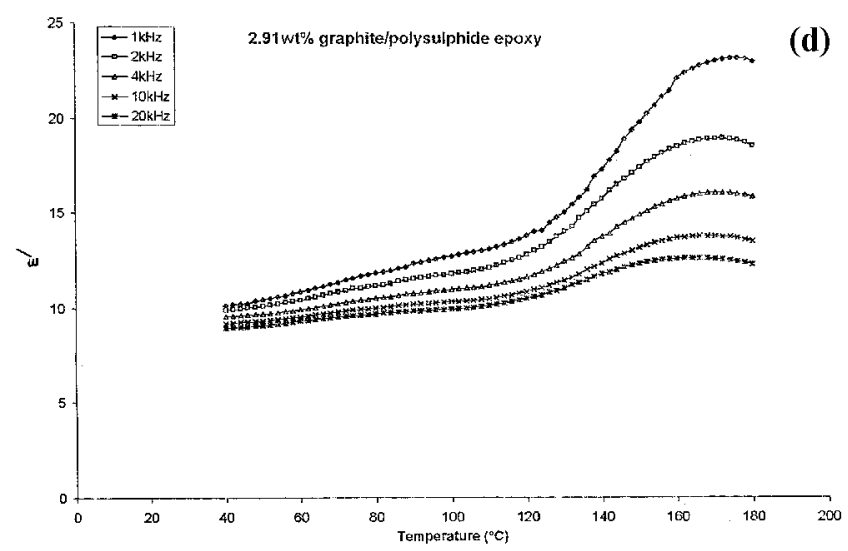

Figure 1. (a) Variation of $\varepsilon^{\prime}$ with temperature for pure polysulphide epoxy at 1,2, 4, 10 and $20 \mathrm{kHz}$ frequencies, (b) variation of $\varepsilon^{\prime}$ with temperature for $0.99 \mathrm{wt} \%$ graphite/epoxy composite at $1,2,4,10$ and $20 \mathrm{kHz}$ frequencies, (c) variation of $\varepsilon^{\prime}$ with temperature for $1.96 \mathrm{wt} \%$ graphite/epoxy composite at $1,2,4,10$ and $20 \mathrm{kHz}$ frequencies and (d) variation of $\varepsilon^{\prime}$ with temperature for $2.91 \mathrm{wt} \%$ graphite/epoxy composite at $1,2,4,10$ and $20 \mathrm{kHz}$ frequencies. 
with increasing frequency. At lower temperature, $\varepsilon^{\prime}$ values at different frequencies merged. Similar trends were observed in case of filled graphite polysulphide epoxy/ composites having $0.99,1.96$ and $2.91 \mathrm{wt} \%$ graphite, respectively. But increase of graphite content increased the $\varepsilon^{\prime}$ value at all the temperatures. It was observed at $40^{\circ} \mathrm{C}$ on adding $2.91 \mathrm{wt} \%$ of graphite. Polysulphide epoxy increased $\varepsilon^{\prime}$ by nearly $100 \%$. This increase in $\varepsilon^{\prime}$ on adding graphite is due to the conducting nature of graphite.

The dielectric constant peaks were observed at $165^{\circ} \mathrm{C}$ for $1 \mathrm{kHz}, 165$ for $2 \mathrm{kHz}, 163$ for $4 \mathrm{kHz}, 163$ for $10 \mathrm{kHz}$ and 163 for $20 \mathrm{kHz}$ at the transition temperature (table 2). Dielectric constant value increases sharply and thereafter remains constant with respect to temperature variation. Dielectric constant peaks shifted to lower temperature side with increasing frequency. This indicates the relaxation behaviour of epoxy resin. $\varepsilon^{\prime}$ peak height reduced on increasing the frequency.

Another interesting observation in dielectric constant $\left(\varepsilon^{\prime}\right)$ vs temperature behaviour of graphite $(0.99 \mathrm{wt} \%)$ filled polysulphide epoxy is that at higher temperature, difference in $\varepsilon^{\prime}$ between $1 \mathrm{kHz}$ and $20 \mathrm{kHz}$ has increased as compared to pure polysulphide epoxy. This increase of $\varepsilon^{\prime}$ value at higher temperatures between $1 \mathrm{kHz}$ and $20 \mathrm{kHz}$ is due to the availability of more space for the easy rotation of dipoles.

$\varepsilon$ ' behaviour of graphite filled polysulphide epoxy composite is very similar to graphite filled polystyrene observed by Xiao et al (2002).

Figures 2(a)-(d) show the variation of $\tan \delta$ vs temperature for pure polysulphide epoxy and 0.99, 1.96 and $2.91 \mathrm{wt} \%$ graphite filled polysulphide epoxy composites, respectively. These plots show that $\tan \delta$ increases with increasing temperature but decreases with increasing frequency. These plots show that $\tan \delta$ peaks in pure polysulphide epoxy resin appeared at $169,169,168$ and $165^{\circ} \mathrm{C}$ corresponding to $2,4,10$ and $20 \mathrm{kHz}$ frequencies, respectively. In case of $0.99 \mathrm{wt} \%$ graphite polysulphide epoxy composite, $\tan \delta$ peak appeared at 167,166 and $164^{\circ} \mathrm{C}$ corresponding to 4,10 and $20 \mathrm{kHz}$ frequencies, respectively. In case of $1.96 \mathrm{wt} \%$ graphite polysulphide epoxy composite, $\tan \delta$ peak appeared at 178,167 and $166^{\circ} \mathrm{C}$ corresponding to 4,10 and $20 \mathrm{kHz}$ frequencies, respectively. In case of $2.91 \mathrm{wt} \%$ graphite polysulphide epoxy composite, $\tan \delta$ peak appeared at $179,178,178,173$ and $171^{\circ} \mathrm{C}$ corresponding to $1,2,4,10$ and $20 \mathrm{kHz}$ frequencies, respec- tively. This shows that in all the cases increase of frequency shifted the $\tan \delta$ peak towards the low frequency side. This $\tan \delta$ peak of epoxy is modified by the addition of graphite. This peak shows a modified relaxation behaviour of epoxy, which is similar to the observation of Lingwal et al (2003). They observed that the tan $\delta$ peak shifted to lower temperature side with decreasing height and increasing frequency, showing the relaxation behaviour.

Figure 2(e) shows the $\log f_{\mathrm{m}}$ vs $1 / T$ plot for graphite filled and unfilled polysulphide modified epoxy.

Figures 3(a)-(d) show the variation of a.c. conductivity with temperature of pure and 0.99, 1.96 and $2.91 \mathrm{wt} \%$ graphite filled polysulphide epoxy composites, respectively.

Figure 3 shows the effect of graphite addition on the a.c. conductivity at different frequencies. Initially at low frequencies increase of graphite content increases the a.c. conductivity linearly and then a peak is observed but as the frequency increases from $4 \mathrm{kHz}$ the increase of a.c. conductivity is continuous. A.c. conductivity peak shifts to left side on increase of frequency. Decrease of a.c. conductivity at higher temperatures is due to increase in free volume of polymer, which reduces the density.

The influence of temperature on a.c. conductivity has been explained by considering the mobility of charge carriers responsible for hopping. As temperature increases the mobility of hopping ions also increases thereby increasing conductivity. The electrons which are involved in hopping are responsible for electronic polarization in these composites. They showed that the conductivity increases up to a temperature of $393 \mathrm{~K}$. Further increase of temperature reduces the conductivity. They explained this decrease in conductivity at higher temperature based on the thermal expansion of polymer. At higher temperatures the polymer density reduced by thermal expansion, which reduces the a.c. conductivity (Sindhu 2002).

Figure 4(a) shows the variation of $\varepsilon^{\prime}$ with graphite $\mathrm{wt} \%$ in graphite/epoxy composites at 1, 2, 4, 10 and $20 \mathrm{kHz}$ frequencies. It was observed that the dielectric constant $\left(\varepsilon^{\prime}\right)$ increases with increasing graphite wt $\%$ at all the frequencies.

Figure 4(b) shows the variation of $\tan \delta$ with graphite wt $\%$ in graphite/epoxy composites at $1,2,4,10$ and $20 \mathrm{kHz}$ frequencies. It was observed that with the addition of graphite initially $\tan \delta$ increased up to $1.96 \mathrm{wt} \%$ and after that it became constant.

Table 2. Peak temperature value.

\begin{tabular}{|c|c|c|c|c|c|c|c|c|c|c|c|c|c|c|c|c|}
\hline \multirow{2}{*}{$\begin{array}{l}\text { Sl. } \\
\text { No. }\end{array}$} & \multirow[b]{2}{*}{ Name } & \multicolumn{3}{|c|}{$1 \mathrm{kHz}$} & \multicolumn{3}{|c|}{$2 \mathrm{kHz}$} & \multicolumn{3}{|c|}{$4 \mathrm{kHz}$} & \multicolumn{3}{|c|}{$10 \mathrm{kHz}$} & \multicolumn{3}{|c|}{$20 \mathrm{kHz}$} \\
\hline & & $\varepsilon^{\prime}$ & $\tan \delta$ & $\sigma_{\text {a.c. }}$ & $\varepsilon^{\prime}$ & $\tan \delta$ & $\sigma_{\text {a.c. }}$ & $\varepsilon^{\prime}$ & $\tan \delta$ & $\sigma_{\text {a.c. }}$ & $\varepsilon^{\prime}$ & $\tan \delta$ & $\sigma_{\text {a.c. }}$ & $\varepsilon^{\prime}$ & $\tan \delta$ & $\sigma_{\text {a.c. }}$ \\
\hline 1. & Polysulphide epoxy & 165 & - & 178 & 165 & 169 & 169 & 163 & 169 & 165 & 163 & 168 & 167 & 163 & 165 & 163 \\
\hline 2. & 0.99 wt $\%$ graphite/epoxy & - & - & - & - & - & - & - & 167 & 167 & 169 & 166 & 169 & 169 & 164 & 169 \\
\hline 3. & $1.96 \mathrm{wt} \%$ graphite/epoxy & 171 & - & - & 171 & - & 178 & 165 & 178 & 175 & 161 & 167 & 167 & 159 & 166 & 167 \\
\hline 4. & $2.91 \mathrm{wt} \%$ graphite/epoxy & 175 & 179 & 178 & 173 & 178 & 179 & 171 & 178 & 177 & 169 & 173 & 173 & 168 & 171 & 171 \\
\hline
\end{tabular}


Figure $4(\mathrm{c})$ shows the variation of $\sigma_{\text {a.c. }}$ conductivity with graphite wt $\%$ in graphite/epoxy composites at 1, 2, 4, 10 and $20 \mathrm{kHz}$ frequencies. Increase of graphite increased a.c. conductivity. At higher frequencies initially a.c. conductivity increased then it showed a plateau after addition of $1.96 \mathrm{wt} \%$ graphite and a.c. conductivity further increased.
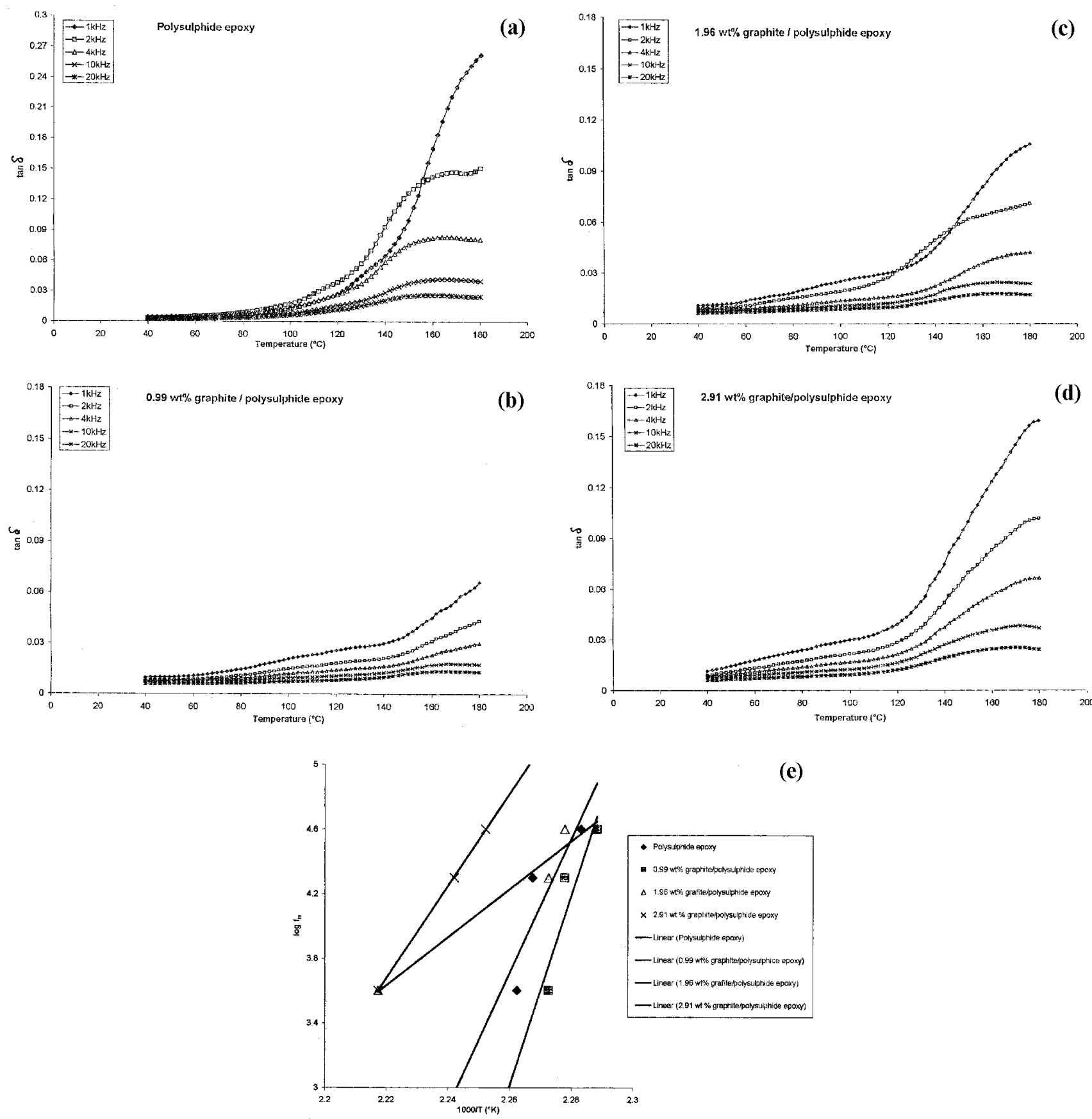

Figure 2. (a) Variation of $\tan \delta$ with temperature for pure polysulphide epoxy at 1,2, 4, 10 and $20 \mathrm{kHz}$ frequencies, (b) variation of $\tan \delta$ with temperature for $0.99 \mathrm{wt} \%$ graphite/epoxy composite at $1,2,4,10$ and $20 \mathrm{kHz}$ frequencies, (c) variation of tan $\delta$ with temperature for $1.96 \mathrm{wt} \%$ graphite/epoxy composite at 1, 2, 4, 10 and $20 \mathrm{kHz}$ frequencies, (d) variation of tan $\delta$ with temperature for $2.91 \mathrm{wt} \%$ graphite/epoxy composite at $1,2,4,10$ and $20 \mathrm{kHz}$ frequencies and (e) shows the $\log f_{\mathrm{m}} \mathrm{vs} 1 / T$ plot for graphite filled and unfilled polysulphide epoxy.

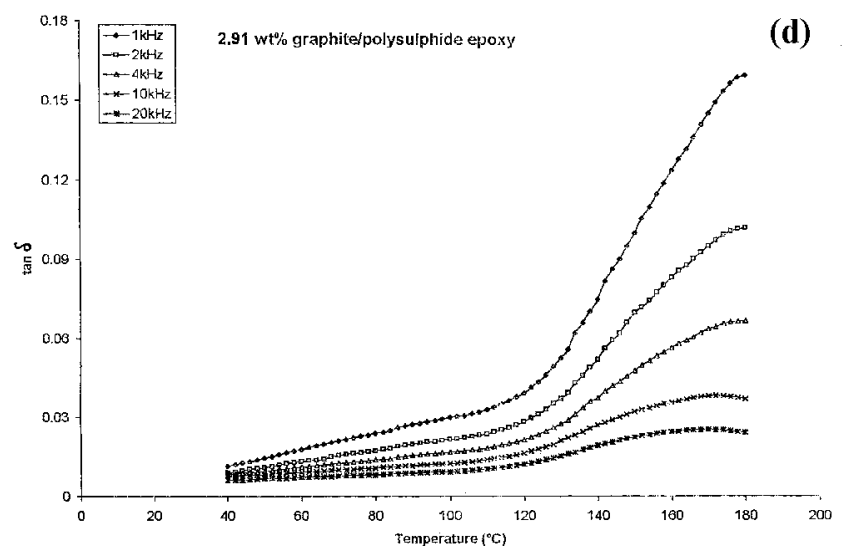

Figure 5(a) shows the variation of $\varepsilon^{\prime}$ vs $\log f$ for pure polysulphide epoxy and $0.99,1.96$ and $2.91 \mathrm{wt} \%$ filled graphite/epoxy composites at $40^{\circ} \mathrm{C}$. It was observed that the dielectric constant decreased with increasing frequency.

Figure 5(b) shows the variation of $\tan \delta$ with $\log f$ for pure polysulphide epoxy and 0.99, 1.96 and $2.91 \mathrm{wt} \%$ filled

) 

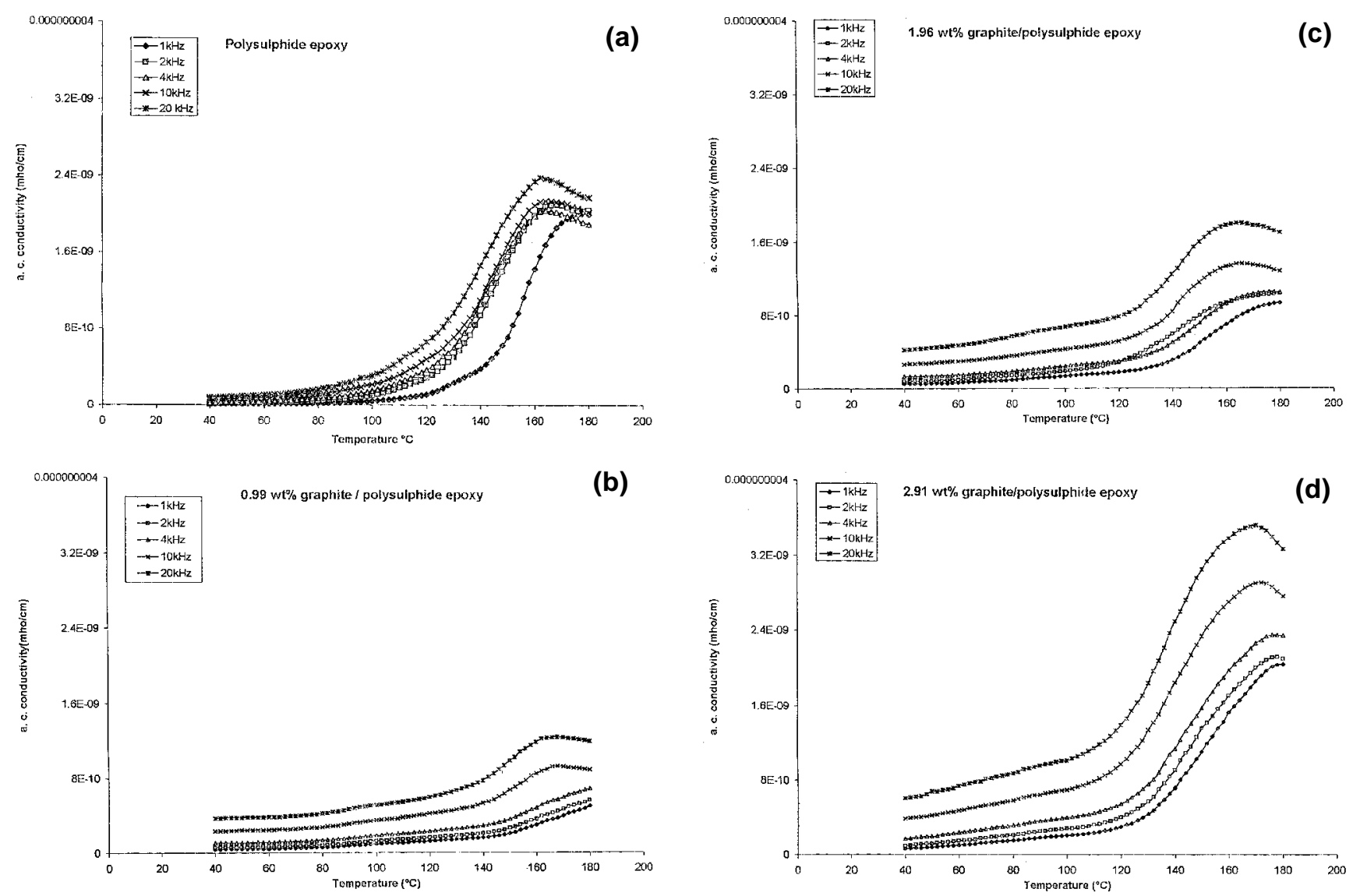

Figure 3. (a) Variation of $\sigma_{\text {a.c. }}$ conductivity with temperature for pure polysulphide epoxy at $1,2,4,10$ and $20 \mathrm{kHz}$ frequencies, (b) variation of $\sigma_{\text {a.c. }}$ conductivity with temperature for $0.99 \mathrm{wt} \%$ graphite/epoxy composite at $1,2,4,10$ and $20 \mathrm{kHz}$ frequencies, (c) variation of $\sigma_{\text {a.c. }}$ conductivity with temperature for $1.96 \mathrm{wt} \%$ graphite/epoxy composite at 1,2, 4, 10 and $20 \mathrm{kHz}$ frequencies and (d) variation of $\sigma_{\text {a.c. }}$ conductivity with temperature for $2.91 \mathrm{wt} \%$ graphite/epoxy composite at 1, 2, 4, 10 and $20 \mathrm{kHz}$ frequencies.

Table 3. Relaxation time, $\tau$ (s), of polysulphide epoxy and polysulphide epoxy/graphite composites at $10 \mathrm{kHz}$.

\begin{tabular}{lcccc}
\hline Temp. $\left({ }^{\circ} \mathrm{C}\right)$ & Polysulphide epoxy & $0.99 \mathrm{wt} \%$ graphite/epoxy & $1.96 \mathrm{wt} \%$ graphite/epoxy & $2.91 \mathrm{wt} \%$ graphite/epoxy \\
\hline 90 & $1.44 \times 10^{-5}$ & $2.94 \times 10^{-5}$ & $3.47 \times 10^{-5}$ & $3.92 \times 10^{-5}$ \\
\hline
\end{tabular}

graphite/epoxy composites at $40^{\circ} \mathrm{C}$. It was observed that the $\tan \delta$ decreased with increasing frequency. There is a sudden increase in $\tan \delta$ value on addition of graphite.

Figure 5(c) shows the variation of a.c. conductivity vs $\log f$ for pure polysulphide epoxy and $0.99,1.96$ and $2.91 \mathrm{wt} \%$ filled graphite/epoxy composites at $40^{\circ} \mathrm{C}$. It was observed that the a.c. conductivity increases with increasing frequency at all frequencies. In case of pure polysulphide epoxy increase of frequency increased the a.c. conductivity up to $4 \mathrm{kHz}$ and then it decreased. Increase of frequency increased a.c. conductivity by increasing the hopping of conducting electrons present in graphite. At higher frequencies this hopping frequency could not match the applied field frequency.

Similar to our observation, frequency dependence of a.c. conductivity has been explained in the past with the help of Maxwell-Wagner (MW) - two-layer model or the heterogeneous model of the polycrystalline structure of ferrites (Koops 1951). According to MW theory two layers form a dielectric structure. The first layer consists of ferrite grains of fairly well conducting (ferrous ions), which is separated by a thin layer of poorly conducting substances, which forms the grain boundary. These grain boundaries are more active at lower frequencies, hence the hopping frequency of electron between $\mathrm{Fe}^{2-}$ and $\mathrm{Fe}^{3+}$ ion is less at lower frequencies. As the frequency of the applied field increased the conductive grains became more active by promoting the hopping of electron between $\mathrm{Fe}^{2+}$ and $\mathrm{Fe}^{3+}$ ions, thereby increasing the hopping frequency. They observed a gradual increase in conductivity with frequency but at higher frequencies the frequency of hopping between the ions could not follow the applied field 
frequency and it lagged behind it. This causes a dip in conductivity at higher frequencies (Sindhu et al 2002).

At low frequencies, a frequency independent conductivity is reported, which is attributed to resistive conduction through the bulk composite. On the other hand, at high frequencies, conductivity appears to be proportional to frequency due to the capacitance of the host medium between
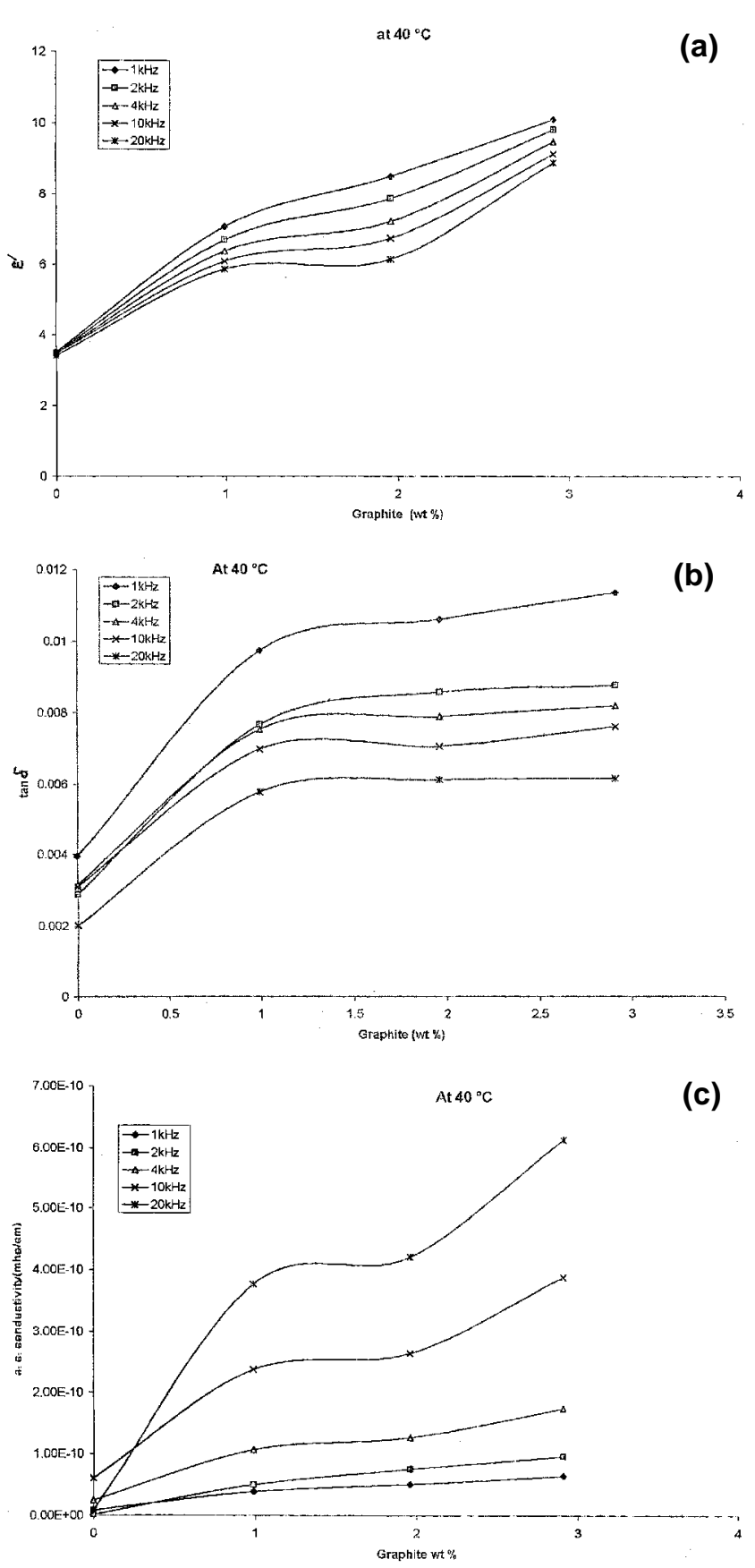

Figure 4. (a) Variation of $\varepsilon^{\prime}$ with graphite wt $\%$ in graphite/ epoxy composites at $1,2,4,10$ and $20 \mathrm{kHz}$ frequencies, (b) variation of $\tan \delta$ with graphite wt\% in graphite/epoxy composites at $1,2,4,10$ and $20 \mathrm{kHz}$ frequencies and (c) variation of $\sigma_{\text {a.c. }}$ conductivity with graphite wt $\%$ in graphite/epoxy composites at $1,2,4,10$ and $20 \mathrm{kHz}$ frequencies. the conducting particles or clusters. They found that a.c. conductivity is both frequency and temperature dependent and increases, up to five orders of magnitude, with increasing frequency and temperature. However, the influence of temperature is more pronounced in the low frequency range. At low frequencies where the applied electric field
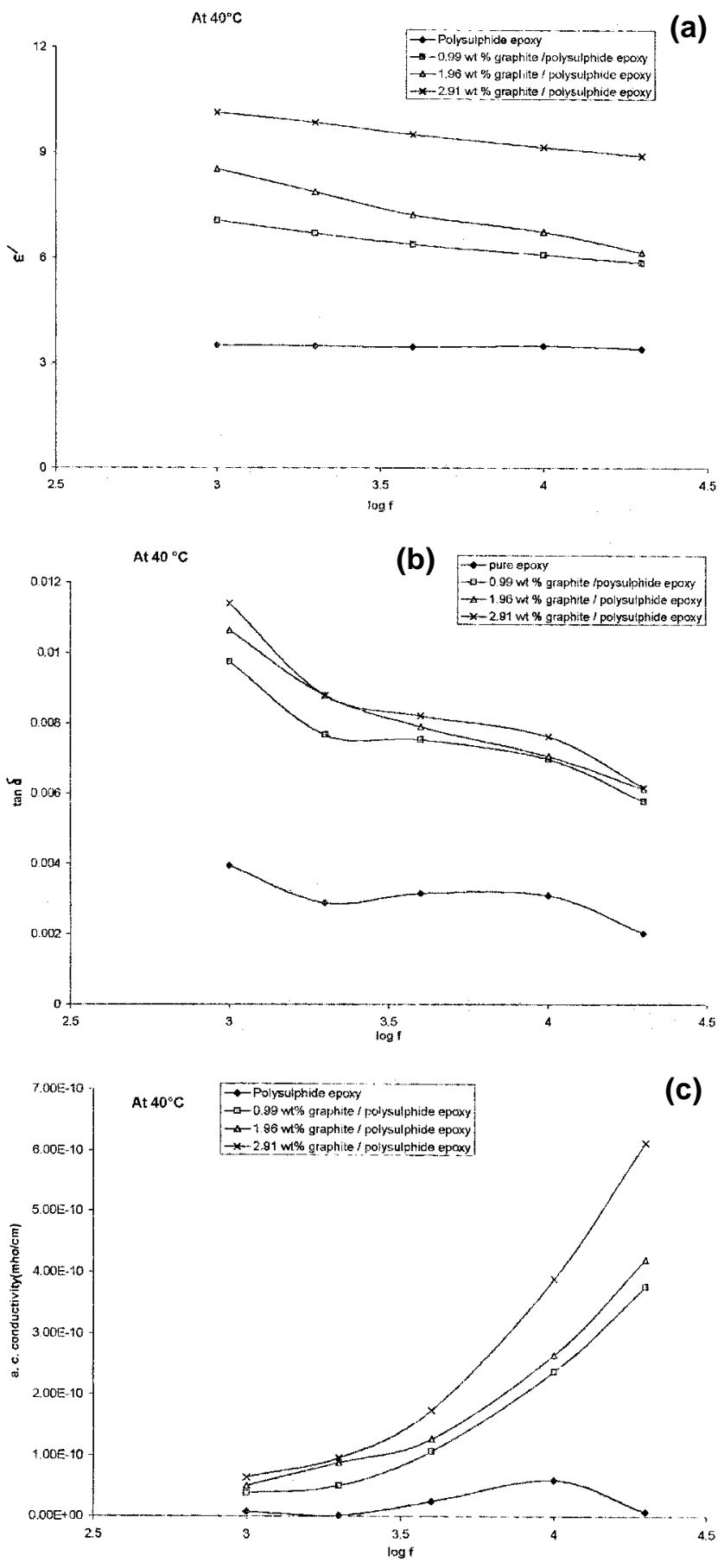

Figure 5. (a) Variation of $\varepsilon^{\prime}$ vs $\log f$ for $0.99,1.96$ and $2.91 \mathrm{wt} \%$ graphite/epoxy composite at $40^{\circ} \mathrm{C}$, (b) variation of $\tan \delta$ vs $\log f$ for $0.99,1.96$ and $2.91 \mathrm{wt} \%$ graphite/epoxy composite at $40^{\circ} \mathrm{C}$ and (c) variation of $\sigma_{\text {a.c. }}$ conductivity vs $\log f$ for $0.99,1.96$ and $2.91 \mathrm{wt} \%$ graphite/epoxy composite at $40^{\circ} \mathrm{C}$. 
forces the charge carriers to drift over large distances, as temperature is increased, a tendency to retain almost constant values is recorded. When frequency is raised, the mean displacement of the charge carriers is reduced and the real part of the conductivity, after reaching a certain critical frequency, $f_{\mathrm{c}}$, follows the law

$$
\sigma_{\text {a.c. }}(\omega) \sim(\omega)^{\mathrm{s}} \text { with } 0 \leq s \leq 1,
$$

characterizing hopping conduction. The critical frequency, $f_{\mathrm{c}}$, has been found to be dependent on temperature and conductive filler volume fraction.

Tsangans et al (1998), Macedo et al (1972), Bakr and North (1977) and Psarras et al (2002) studied the dielectric relaxations in filled polymers and found that the presence of conductive particles modified dielectric relaxations. Interfacial polarization has been observed in heterogeneous systems.

Psarras et al (2002) reported that the increase in temperature increased the dielectric constant due to increased segmental mobility of the polymer molecules, which leads to an increase in dielectric constant. Differential thermal expansion of the polymer and the metal disrupts the chains of contacting particles and decreases the dielectric constant. Near the glass transition temperature $\left(T_{\mathrm{g}}\right)$ segmental mobility of the polymer molecules is a dominating factor which increases the dielectric constant.

Chand (1980) reported that the relaxation time is an important factor which can be determined from the dielectric data. Influence of graphite addition on the structure of polysulphide epoxy resin can be understood by knowing the relaxation time of graphite filled and unfilled polysulphide modified epoxy systems. Relaxation time of graphite filled and unfilled polysulphide epoxy system has been calculated by the equation reported by Chand (1980).

$$
\tau=1 / \omega\left[\sqrt{ }\left(\left(\varepsilon_{0}-\varepsilon_{\infty}\right) /\left(\varepsilon^{\prime}-\varepsilon_{\infty}\right)\right)-1\right] .
$$

Relaxation time of pure polysulphide epoxy at $90^{\circ} \mathrm{C}$ has been found to be $1.44 \times 10^{-5} \mathrm{~s}$. This value of relaxation time is nearly same as reported in literature (Tsuneo and Noritoshi 1998). Relaxation time of pure polysulphide epoxy at $90^{\circ} \mathrm{C}$ and at $10 \mathrm{kHz}$ frequency increased from $1.44 \times$ $10^{-5}$ to $3.92 \times 10^{-5}(\mathrm{~s})$ on addition of $2.91 \mathrm{wt} \%$ graphite to polysulphide epoxy (table 3 ). Increase of relaxation time at this temperature on addition of graphite can be explained on the basis of increased disruption created by graphite particles.

\section{Conclusions}

(I) Clear relaxation tan $\delta$ peaks around $169^{\circ} \mathrm{C}$ were observed in epoxy resin, which shifted to lower temperature side on increasing the frequency.

(II) Addition of $2.91 \mathrm{wt} \%$ graphite shifted the $\tan \delta$ peaks towards higher temperature side by creating hindrances in the rotation of polymer dipoles.

(III) Increase of frequency increased a.c. conductivity initially and at higher frequencies there was a dip in the trend due to the mismatch of dipole frequency and applied field frequency.

(IV) Relaxation time of pure polysulphide epoxy increased from $1.44 \times 10^{-5}$ to $3.92 \times 10^{-5}$ (s) at $90^{\circ} \mathrm{C}$ and at $10 \mathrm{kHz}$ frequency on addition of graphite.

\section{References}

Bakr A A and North A M 1977 Eur. Polym. Sci. 13799

Chand N $1980 \mathrm{Ph}$. D. thesis, IIT, New Delhi

Delmonte J 1990 Metal/polymer composites (New York: Van Nostrand Reinhold) p. 4

Koops C G 1951 Phys. Rev. 83121

Lingwal V, Semwal B S and Panwar N S 2003 Bull. Mater. Sci. 26619

Macedo P B, Moynihan C T and Bose R 1972 Phys. Chem. Glasses 13171

Neelakanta P S 1995 Handbook of electromagnetic materials (Boca Raton: CRC Press) p. 7

Psarras G C, Manolakak E and Tsangaris G M 2002 Composite: Part A 33375

Sindhu S, Anantharaman M R, Bindu P Thampi, Malini K A and Kurian P 2002 Bull. Mater. Sci. 25599

Tsangans G M, Psarras G C and Kouloumbi N 1998 J. Mater. Sci. 332027

Tstra P and Freidrich K 2003 Composite Part A: Appl. Sci. \& Manuf. 3475

Tsuneo K and Noritoshi I 1998 Polym. Eng. Sci. 381838

Wu S L and Tung Chun 1995 J. Polym. Comp. 16233

Xiao M, Sun L, Liu J, Li Y and Gong K 2002 Polymer 43 2245 